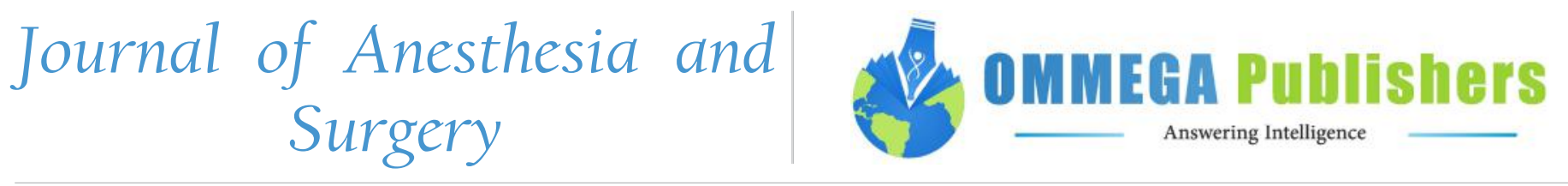

Case Report

\title{
Anaesthesia challenges in a Patient with Hurler Syndrome: A Case Report
}

\author{
Muhammad Asghar Ali* and Khalid Maudood Siddiqui
}

Department of Anesthesia, Aga Khan University, Karachi, Pakistan

*Corresponding author: Muhammad Asghar Ali, Assistant Professor, Department of Anesthesia, Aga Khan University, Karachi, Pakistan, Tel: 0922134864636/03333306229; E-mail: asghar.ashraf@aku.edu

\begin{abstract}
Mucopolysaccharidosis (MPS) is a group of inherited disorders of connective tissue metabolism. Although these disorders are rare but often these patients undergo multiple surgeries under anaesthesia to improve their quality of life. We are describing here the anaesthetic considerations and management of a 7 year old child with Hurler syndrome, who presented for an Adenotonsillectomy.
\end{abstract}

Keywords: Difficult airway; Anesthetic management; Hurler syndrome

\section{Introduction}

Hurler syndrome is a rare metabolic disorder. It is a genetically transmitted lysosomal storage disease, resulting in accumulation of acid mucopolysaccharides in the central nervous system and peripheral tissue. These children frequently present with difficulties in airway management, because of an enlarged tongue and limited movement of neck and perilayngeal tissue. The incidences of difficult and failed intubation are $54 \%$ and $23 \%$ respectively, which increases with age. Anaesthetic management of patients with Hurler syndrome is challenging \& needs to be well planned. Recent advances like stem cell transplant, bone marrow transplant $\&$ enzyme replacement therapy will increase life expectancy of such patients. So, coming generation of anesthesiologists is more likely to see greater number of such patients in near future.

\section{Case Report}

Our Patient was a 7 year old female child. She was a known case of Hurler syndrome and presented to us for adenotonsillectomy. She was short in stature, weighing $15 \mathrm{~kg}$, an apathetic face with wide nasal bridge, flattened midface and coarse features (Figure $1 \& 2$ ). She also had attention deficit along with mild mental retardation and hyperkinetic behavior. Her developmental milestones were delayed. In preoperative assessment, child was otherwise healthy with no other comorbids. Systemic examination was normal except 4/6 pansystolic murmur on auscultation of mitral area of the heart. The airway examination revealed normal mouth opening, more than 3 fingers but thick and large tongue along with short neck with limited extension. Her Mallampati score was grade III and thyro mental distance was less than 3 finger as well as limited extension on atlanto- occipital joint. All laboratory investigations were within normal range. Echocardiography showed thickened myxomatous both mitral valve leaflets with mitral valve prolapse, moderate mitral regurgitation. After taking the patient in operating room, standard ASA monitoring
Citation: Muhammad A.A., et al. Anaesthesia challenges in a Patient with Hurler Syndrome: A Case Report. (2015) J Anesth Surg 2 (2): 43-45.

Received date: April 03, 2015
Accepted date: June 30, 2015
Published date: July 07, 2015

DOI: $10.15436 / 2377-1364.15 .018$

(ECG, NIBP and $\mathrm{SpO}_{2}$ ), was applied. A 20 gauge intravenous cannula was placed on left hand and Ringer's lactate started as maintenance fluid. After three minutes of preoxygenation, intravenous propofol 30 $\mathrm{mg}$ was given, ventilation was assessed that was easy, and so atracurium $7.5 \mathrm{mg}$ was given. After three minutes of manual ventilation, laryngoscopy was done. Laryngeal structures were not visible even after posterior displacement of laryngeal cartilage by using Backward Upward Right Pressure (BURP). After two attempts of intubation tip of thick, circular epiglottis was seen but could not lift epiglottis. During next attempt with a straight blade laryngoscope with cricoid pressure by the assistant improved the laryngeal view. Finally a thin smooth plastic pediatric bougie was introduced along the posterior surface of epiglottis. A $5.0 \mathrm{~mm}$ ID un cuff endotracheal tube (ETT) was passed over the bougie, ETT was connected to Jackson Rees circuit and manual ventilation was started. Anaesthesia was maintained with oxygen, nitrous oxide and isoflurane. Intravenous fentanyl $2 \mathrm{ug} / \mathrm{kg}$ was given to maintain

Copy rights: (C2015 Muhammad A.A. This is an Open access article distributed under the terms of Creative Commons Attribution 4.0 International License. 
intraoperative analgesia. Surgery was allowed, when surgeon put the Boyle-Davis mouth gag, it made the ventilation difficult, Mouth gag was readjusted 3 - 4 times but the same problem was faced persistently and ventilation was becoming more difficult. Meanwhile patient developed severe bronchospasm; there were no chest movements, breath sounds, or end-tidal carbon dioxide. She was given four doses of albuterol aerosol through the endotracheal tube, and ventilation was attempted again with $8 \%$ sevoflurane in $\mathrm{O}_{2}$. After that it became possible to ventilate with small tidal volumes and ventilating pressures between 20 and 30 $\mathrm{cm} \mathrm{H}_{2} \mathrm{O} . \mathrm{O}_{2}$ saturations began to increase, and wheezing breath sounds could now be heard. A treatment of $2.5 \mathrm{mg}$ nebulized albuterol was administered through the endotracheal tube. During the ensuing $5 \mathrm{~min}$, manual ventilation became progressively easier with tidal volumes increasing to $70-100 \mathrm{ml}$ at pressures of $15-20 \mathrm{~cm} \mathrm{H}_{2} \mathrm{O}$. The patient's $\mathrm{O}_{2}$ saturation increased to $100 \%$, breath sounds returned to normal. Anesthesia was continued in circle system with $2-4 \%$ sevoflurane, $0.5 \mathrm{l} / \mathrm{min} \mathrm{O}_{2}$, and 0.5 $1 /$ min $\mathrm{N}_{2} \mathrm{O}$. Atracurium $2.5 \mathrm{mg}$ was required to assist with relaxation. Surgery proceeded uneventfully with the removal of adenoids and tonsils. Muscle relaxation was reversed with 0.75 neostigmine and $0.3 \mathrm{mg}$ atropine. With the patient spontaneously breathing, volumes of $120-150 \mathrm{ml}$ at a respiratory rate of 16 breaths $/ \mathrm{min}$, and patient became fully awake, we elected to extubate the patient, oropharynx were thoroughly suctioned, and the endotracheal tube was removed. She continued to breathe $100 \% \mathrm{O}_{2}$ spontaneously, awoke, and was transferred to the post anesthesia care unit, where her $\mathrm{O}_{2}$ saturation with room air was $99-100 \%$ and her chest was clear. She was transferred to the pediatric unit and was discharged on the $3^{\text {rd }}$ postoperative day.

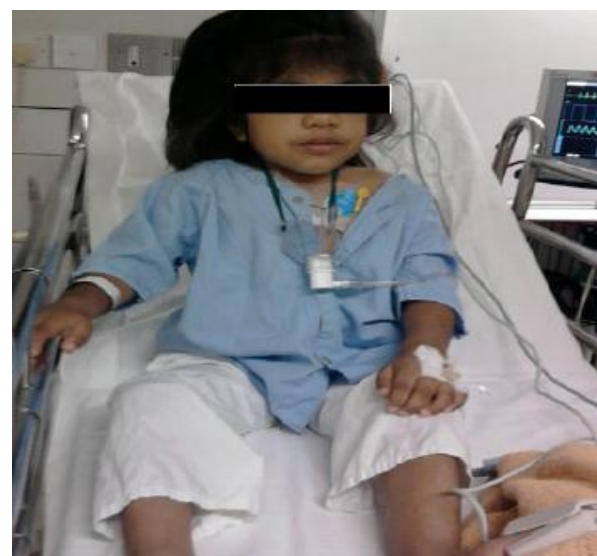

Figure 1

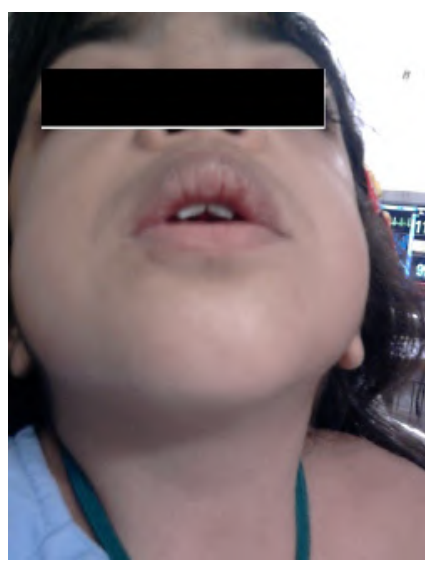

\section{Discussion}

Hurler syndrome is the prototype of MPS and it is the most severe form of $i^{[1]}$. In Hurler syndrome airway related problems have been described in literature ${ }^{[2]}$. Perioperative mortality rates averaging $20 \%$ have been reported for patients with this disease, with failure to control the airway as the major cause of mortality ${ }^{[3]}$. MPS is a rare condition, incidence varying from 1 in 24,000 - 5, 00,000 population. The anesthesiologist may face diverse problems while anaesthetizing these patients, so knowledge of the anesthetic implication of the disease is essential to prevent any catastrophe ${ }^{[4]}$. The most important and life threatening problem is difficulty in maintaining airway while anaesthetizing such patients because of the anatomical changes in upper airway due to deposition of mucopolysaccharides in tongue, tonsils, adenoid, epiglottis, glottis and trachea. These patients also have excessive tracheobronchial secretion with frequent respiratory tract infection ${ }^{[5]}$. Chest deformity along with interstitial lung disease may lead to hypercarbia, hypoxia and elevated airway pressures. They are also prone to develop myocardial hypertrophy, ventricular dysfunction, cardiomyopathy and heart failure following pulmonary hypertension ${ }^{[6]}$. Nerve and tendon entrapment is common in these patients. Due to deposition of mucopolysaccharides in brain cells they may develop progressive mental retardation of varying degree. Thickening of meninges may lead to hydrocephalus and hypertrophic cervical pachymeningitis that may result in myelopathy associated with nerve root compression. In Children with MPS, behavior may vary from uncooperative belligerent to placid, cooperative and lovable. Child's favorable sleeping position should be inquired, since this may be the position in which airway is held open. History of snoring and sleep apnea should be inquired. Preoperative investigations should include arterial blood gas analysis, hemoglobin, serum electrolytes, chest and cervical spine radiographs, electrocardiography, echocardiography and pulmonary function tests if possible. In our case the child was thoroughly investigated for blood chemistry, ECG, echocardiography and skeletal radiography. SBE prophylaxis with antibiotics is recommended for all MPS patients with valvular cardiac lesion ${ }^{[7]}$. In all cases of MPS excessive deposition of mucopolysaccharides continues throughout the life with a special predilection for tracheal cartilages, worsening clinical features in all of them as age advances.

In our case, the child" ventilation was assessed after giving intravenous propofol keeping in view of difficult airway. Recovery after general anaesthesia in patients with MPS is often slow and accompanied by periods of breath holding, apnea, bronchospasm, cyanosis and respiratory arrest. Therefore anesthetic sequences which ensure early return of consciousness and airway reflexes are strongly recommended. As an awakened child with MPS struggles to breathe against the high airway resistance, pulmonary hypertension is exacerbated and negative pressure pulmonary edema may develop. Well thought anaesthetic plan is necessary before the induction of case; equipments related to managing difficult airway should be prepared including fiberoptic bronchoscope. In managing two similar cases Gupta, et al. observed Cormack-Lehane (CL) grade IV and III subsequently ${ }^{[8]}$. It is now established that patients with hurler syndrome has challenge to anesthesiologist particularly airway is concern.

Figure 2 
Regional anesthesia offers a valuable safe alternative to children with MPS undergoing lower abdominal, perineal, upper and lower extremity surgery and should be preferred over GA if cooperation of child is ensured. In children with MPS, both anesthesiologist and surgeons should be aware of the expected complications. The benefit of the surgical procedure should be balanced against the risk of exposing the child to GA. Risk related to anaesthesia should be informed to the parents. Anesthesia should ideally be given by the anesthesiologists who are experts in handling pediatric airway problems and resuscitation. This case should be done in specialize center, where pediatric intensive care unit facilities are available. The gold standard tool for difficult airway management is flexible bronchoscope but new modalities are also effective like video laryngoscope, airtraq optical laryngoscope, glidescope cobalt, trophatek $\mathrm{EVO}_{2}$, optical stylets, Bonfils fiberscope and lighted stylets.

Treatment of Hurler syndrome can be done by enzyme replacement therapy. Enzyme replacement therapy adds a working form of the missing lysosomal alpha-L-iduronidase enzyme to the person with Hurler syndrome's body. Another form of treatment option may include bone marrow transplantation. Bone marrow transplant has been used in a number of people with Hurler syndrome. Use of bone marrow transplants has had mixed results in persons with Hurler syndrome. Other forms of treatment that may be ordered by a doctor or applied depend upon the particular organ that has been affected by the syndrome.

\section{Conclusion}

In children with MPS, both anesthesiologist and surgeons should be aware of the expected complications. The benefit of the surgical procedure should be balanced against the risk of exposing the child to GA. The parents of the patient should properly be informed of the risk involved. Anesthesia should ideally be given by the anesthesiologists who are experts in handling pediatric airway problems and resuscitation, in a center in which pediatric intensive care facilities are available.

\section{References}

1. Gupta, A.K., Kharde, D.V., Gawer, D.V., et al. Hurler Syndrome: Anaesthetic Challenges and Management. (2010) Anestesia Pediatrica e Neonatale $8(2)$.

2. Muhlebach, M.S., Wooten, W., Muenzer, J. Respiratory manifestations in mucopolysaccharidoses. (2011) Paediatr Respir Rev 2(2): 133138.

3. Wilder, R.T., Belani, K.G. Fiberoptic intubation complicated by pulmonary edema in a 12- year-old child with Hurler syndrome. (1990) Anesthesiology 72(1): 205-207.

4. Daryoush Sheikhzadeh MD. Cardiac Arrest in a Case of Mucopolysaccharidosis after Tracheostomy. (2010) J Cardiovasc Thorac Res 2(1): 51-53.

5. Kaur, J., Swami, A.C., Kuma,r A., et al. Anesthetic management of a child with Hunter's syndrome. (2012) J Anaesthesiol Clin Pharmacol 28(2): 255-257.

6. Braunlin, E.A., Harmatz, P.R., Scarpa, M., et al. Cardiac disease in patients with mucopolysaccharidosis: presentation, diagnosis and management. (2011) J Inherit Metab Dis 34(6): 1-15.

7. Muenzer, J., Wraith, J.E., Clarke, L.A. Mucopolysaccharidosis I: management and treatment guidelines. (2009) Pediatrics 123(1): 19-29. 8. Gupta, N., Rath, G.P., Bala, R., et al. Anesthetic management in children with Hurler's syndrome undergoing emergency ventriculoperitoneal shunt surgery. (2012) Saudi J Anaesth 6(2): 178-180.
Ommega Online Publishers

Journal Title: Journal of Anesthesia and Surgery (JAS)

Journal Short Name: J Anesth Surg
Journal ISSN: 2377-1364

E-mail: anestheisa@ommegaonline.com Website: www.ommegaonline.org 